\title{
Predictors of Physical Health: Toward an Integrated Model of Genetic and Environmental Antecedents
}

\author{
Wendy Johnson and Robert F. Krueger
}

Department of Psychology, University of Minnesota-Twin Cities, Minneapolis.

\begin{abstract}
People in higher-income groups tend to experience better physical health, yet this does not appear to be the direct result of access to medical care. This has prompted a search for psychological factors more likely to be present in high-income environments that might help to explain the relationship. Physical health has been associated with a number of such psychological measures including positive affect and well-being, negative affect and neuroticism, positive social relationships, and perceived control. Building from recent findings of moderation of genetic variance in physical health by income and perceived control, we explore the genetic and environmental relationships among all these variables in a nationwide U.S. twin sample. These relationships suggest possible mechanisms by which psychological characteristics, behaviors, physical health, and environmental circumstances could be influenced by common groups of genes with varying degrees of activity in different environments. We discuss the implications of such mechanisms for differential expression of genetic variation in the population and suggest ways in which consideration of such effects can inform gerontology research.
\end{abstract}

$\mathrm{T}_{\mathrm{t}}$ HE WELL-ESTABLISHED (Adler \& Snibbe, 2003) differences in physical health and mortality associated with markers of social class, including income, education, and occupation, raise clear issues for gerontologic research as well as social and political issues for the aging populations that are pervasive across much of the Western world. The differences persist over time, across geographic settings, over the full range of income, and for almost every disease and condition, including accidental injuries (Adler et al., 1994). Though there is some evidence that poor health contributes to low income and social class, the evidence for income and social class effects on physical health is much stronger (Haan, Kaplan, \& Syme, 1989). The most obvious possible explanation has been that disparities in health result from disparities in resources including access to medical care. This explanation seems inadequate, however, in the face of evidence that more equal access to and general improvements in health care, along with falling rates of mortality and morbidity, tend to widen income and social class disparities in health (Steenland, Henley, \& Thun, 2002). That is, differences in health outcomes by income and social class actually get larger when available health care resources become more even across class lines.

This has prompted a search for mediating psychological variables varying with income and social class that may initiate biological mechanisms that in turn affect health status. The focus has been on increased psychological stress in low-income environments, generated by a greater mismatch between physical and social demands and resources including subjective social status (Adler, Epel, Castellazzo, \& Ickovics, 2000), leading over time to greater physical wear and tear and thus to deterioration in health (Adler \& Snibbe, 2003). These explanations emphasize the responsibility of income inequalities over other aspects of social class such as education and occupation for the disparities in health, and the disparities in health are observed consistently with measures of income alone (Adler \& Snibbe, 2003). There is evidence for the existence of psychological stress mechanisms that lead to deterioration in health (Adler et al., 2000; McEwen, 1998), but the available evidence suggests that their mediating effects on the association between health and income alone are small in comparison with the overall relationship between the two.

When two variables $A$ and $B$ are correlated, there are three (not mutually exclusive) explanations for the association: (1) $A$ causes $B$, (2) $B$ causes $A$, and (3) some additional variable(s) $C$ cause(s) both $A$ and $B$. With respect to the association between income and health, the third explanation has generally been dismissed as potentially "blaming the victim" (e.g., Cramer, 1995 , p. 234) or tending to "absolve the social structure of responsibility" (Wilkinson, 1996, p. 63). Thus, intervening variables that could serve overall causative roles in the association between income and health have generally been proffered only in a form that allows the differences themselves to result from external social conditions: that is, remaining within the $A$ causes $B$ framework, in the form of an $A$ causes $C$, which in turn causes $B$ model. Given the failure of the $A$ causes $B$ or $B$ causes $A$ (possibly with intervening variables) explanations to account for the full extent of the association between physical health and income, however, extending the investigation to consideration of the third explanation ( $C$ causes both $A$ and $B$ ) as well would appear to be warranted. The purpose of this article is to explore the various general causative agents that have been offered from all three perspectives, with emphasis on the ways in which decomposition of the genetic and environmental influences underlying the association can illuminate the underlying processes. Several classes of variables associated with income that might exert causative influences on physical health have been suggested. Broadly summarized, we will discuss them as negative and positive affect, social relationships, and perceived control over life.

\section{Potential Causes of Differences in Health Associated With Income}

\section{Negative and Positive Affect}

Negative affect has consistently been associated with both low income and adverse effects on physical health, particularly 
when physical health is self-reported (Gallo \& Mathews, 2003). The association has been perceived to result because psychosocial stressors trigger negative affect as one of several stress responses, and these responses lead over time to the emergence of health problems (McEwen, 1998). There are data from experimental animals corroborating this hypothesis (Parsons, 2003). For example, in Drosophila melanogaster, genetic variability for fitness, and especially mortality, increases in situations of high stress (Parsons, 2002). But the evaluation of the hypothesis in humans is complicated by the fact that selfreport measures of both stress and physical health reflect personality trait-level negative affect, yet this trait itself does not appear to be related to long-term, objectively rated health status (Watson \& Pennebaker, 1989). This suggests that, at a minimum, any association between negative affect or stress and actual physical health will be overstated as these variables are typically measured in health research.

It is not clear, however, how negative affect actually impacts reports of health and stress, and some studies that have included corrections for negative affect common to stress and health have still found significant relationships (e.g., Leventhal, Hansell, Diefenbach, Leventhal, \& Glass, 1996; Maddi \& Khoshaba, 1994). It is possible that people high in negative affect tend to exaggerate negative experiences and sensations, but it is also possible that people low in negative affect disregard negative experiences and sensations (Judge, Erez, \& Thoresen, 2000). If the latter were true, the reports of those high in negative affect would be more accurate, which might provide an explanation for the observed pattern of associations. Pennebaker, Czajka, Cropanzano, and Richards (1990) provided evidence that presentation of unavoidable stress in the form of intrusive noise during task performance was associated with more narrow and superficial thinking. Habitual use of such thinking, however, was associated with greater visits to a health center, greater consumption of pain relief medicine, and greater consumption of alcohol. On the other hand, presentation of intrusive noise that could be terminated did not result in more narrow and superficial thinking, but it did result in greater expression of negative emotion. Pennebaker and colleagues (1990) suggested that more sophisticated acknowledgment of negative emotions might be an important way of coping with occasional psychological crises, but living continuously with such internal conflict might erode physical health. At the same time, whereas disregarding minor annoyances may be adaptive, disregarding more important stressors may blind individuals to coping strategies as well as placing them under additional physiologic stress (Langer, 1989; Pennebaker, 1990; Pennebaker, Hughes, \& O’Heeron, 1987). Clearly, testing nonlinear mechanisms such as this will require subtle measurement instruments.

In contrast to early findings regarding negative affect and health, initial investigations of the relationship between positive affect and health did not yield significant results (Beiser, 1974; Dua, 1993; Watson \& Pennebaker, 1989). In addition, there is little evidence for an association between positive affect and social class (Lykken, 2000). More recent work, however, has provided a different picture at least for an association between positive affect and health at the level of objective measures of health. Frederickson and Levenson (1998) showed participants a negative emotion-inducing film, which aroused the sympathetic nervous system and increased cardiovascular activity.
Participants who subsequently viewed a positive emotioninducing film recovered more quickly to baseline levels than did participants who subsequently viewed either a negative or a neutral film. The authors suggested that positive emotions might play a homeostatic role in maintaining physiologic equilibrium, which might help to mitigate the effects of stress. Positive emotions and trait optimism have also been linked to increased immune system function (Levy, Herberman, Maluish, Schlien, \& Lippman, 1985; Schier \& Carver, 1987). Taken together, these findings suggest a web of interrelationships among the states and traits of negative and positive affect and physical health, with the mood states having stronger relationships to objective health status and the traits acting primarily as nuisance factors in measuring the effects of the mood states (Diefenbach, Leventhal, Leventhal, \& Patrick-Miller, 1996; Leventhal et al., 1996). In considering the link between income and physical health, negative affect has been presumed to result from the relatively unpleasant conditions associated with lower social class, but neither the actual degree of association nor the presumed direction of association has been explored thoroughly, to our knowledge.

\section{Social Relationships}

Considerable evidence has also been compiled for an association between social relationships and physical health. Epidemiologists have consistently shown that social isolation or perceived lack of social support is linked to greater incidence of disease as well as to increased mortality (Berkman \& Breslow, 1983; Berkman \& Syme, 1979; House, Landis, \& Umberson, 1988). Though social connection and perceived social support appear to have a main effect on health, they appear to be particularly beneficial when one is confronted by crisis, stress, and/or adversity (Cohen, 1988). It is these conditions that are more common among people of lower income. Thus, as with negative affect, the direction of association from income to the perception of social support and from social support to health effects has largely been presumed, though it is clear that people of higher social class may be in a better position to direct more resources to the acquisition of social support. The question of the relationship between perceived social support and income is important, however, because the emotional features of social relationships generating support rather than their quantity are likely to mediate their association with physical health, as are the emotional features likely to activate the underlying physiologic processes (Ryff \& Singer, 2001). That is, negative relationships and/or loneliness may arouse negative emotions, with the deleterious effects on health discussed above, whereas positive relationships may arouse positive emotions with very different effects on health, leaving social relationships with only a moderating (rather than mediating) role in the association between social class and physical health.

This hypothesis results from two issues about the involvement of social relationships in physical health. First, it may not be the actual receipt of social support that accounts for health benefits. A meta-analysis of the association produced inconsistent findings (Smith, Fernengel, Holcroft, Gerald, \& Marien, 1994), with support in some instances actually being harmful. It is easy to conceive of reasons for this: Depending on others for support can cause guilt and anxiety (Lu \& Argyle, 1992), and mourning lost autonomy could cause depression. In fact, in 
Table 1. Correlations Among Variables Associated With Social Class Differences in Health

\begin{tabular}{|c|c|c|c|c|c|c|c|c|c|c|c|c|c|}
\hline Variable & 1 & 2 & 3 & 4 & 5 & 6 & 7 & 8 & 9 & 10 & 11 & 12 & 13 \\
\hline 1. Purpose & 1.00 & .24 & .17 & .20 & .22 & .14 & .10 & .16 & -.22 & -.28 & -.13 & -.08 & .22 \\
\hline 2. Control & .24 & 1.00 & .46 & .31 & .32 & .15 & .26 & .48 & -.32 & -.43 & -.25 & -.11 & .11 \\
\hline 3. Spouse relations & .17 & .46 & 1.00 & .28 & .34 & .17 & .11 & .31 & -.28 & -.35 & -.13 & -.08 & .03 \\
\hline 4. Friend relations & .20 & .31 & .28 & 1.00 & .44 & .17 & .23 & .28 & -.23 & -.29 & -.13 & -.08 & .08 \\
\hline 5. Family relations & .22 & .32 & .34 & .44 & 1.00 & .39 & .14 & .30 & -.28 & -.36 & -.20 & -.14 & .13 \\
\hline 6. Twin relations & .14 & .15 & .17 & .17 & .39 & 1.00 & -.01 & .12 & -.15 & -.19 & -.12 & -.08 & .12 \\
\hline 7. Extraversion & .10 & .26 & .11 & .23 & .14 & -.01 & 1.00 & .38 & -.14 & -.20 & -.06 & -.03 & .03 \\
\hline 8. Good mood & .16 & .48 & .31 & .28 & .30 & .12 & .38 & 1.00 & -.47 & -.60 & -.33 & -.07 & .06 \\
\hline 9. Neuroticism & -.22 & -.32 & -.28 & -.23 & -.28 & -.15 & -.14 & -.47 & 1.00 & .54 & .30 & .06 & -.08 \\
\hline 10. Bad mood & -.28 & -.43 & -.35 & -.29 & -.36 & -.19 & -.20 & -.60 & .54 & 1.00 & .37 & .11 & -.13 \\
\hline 11. Chronic illnesses & -.13 & -.25 & -.13 & -.13 & -.20 & -.12 & -.06 & -.33 & .30 & .37 & 1.00 & .16 & -.11 \\
\hline 12. Body mass index & -.08 & -.11 & -.08 & -.08 & -.14 & -.08 & -.03 & -.07 & .06 & .11 & .16 & 1.00 & -.11 \\
\hline 13. Income & .22 & .11 & .03 & .08 & .13 & .12 & .03 & .06 & -.08 & -.13 & -.11 & -.11 & 1.00 \\
\hline
\end{tabular}

Note: Correlations of absolute value of .09 or more were significant at $p<.01$ (corrected for dependence between members of twin pairs by weighting each twin $1 / 2)$.

a study directly comparing the effects of giving and receiving support on longevity in older married adults, Brown, Nesse, Vinokur, and Smith (2003) found that, after controlling for the effect of giving support, there was no effect of receiving support. The relationships of giving and receiving support with mortality were complicated by the role of dependence: Receiving emotional support reduced the risk of mortality when dependence, but not giving support, was controlled but increased the risk when giving support, but not dependence, was controlled. It seems likely that the beneficial effects on health associated with social relationships involve a close matching of individual needs for and availability of social contact of various kinds rather than some overall level and type of social contact and that the effects are intimately connected with the nature of the emotional responses generated by the relationships.

The second issue regarding the involvement of social relationships in physical health relates to the measurement of the effect of social relationships on health, given that social relationships directly involve emotional responses. Like selfreports of physical health, self-reports of the quality of social relationships are likely also contaminated by trait-level negative affect, thus inflating the association between the two. Kahn, Hessling, and Russell (2003) provided some evidence that this is, in fact, the case. On the other hand, it is possible that people who are high in negative affect experience more difficulty establishing positive social relationships because others find them more difficult company. After all, difficulty in social relationships is generally one of the markers of negative affect. For example, in Tellegen's (in press) Multidimensional Personality Questionnaire, scores on the Alienation Scale, which reflect the perception of hostile relations with others, contribute directly to the measure of negative affect. Angry hostility is also one of the facets of neuroticism in the NEO Personality Inventory Revised (Costa \& McCrae, 1992). This suggests that merely controlling for the presence of trait-level negative affect in the assessment of the relationship between social relationships and health may be overly simplistic.

\section{Perceived Control}

Perceived control over life outcomes has also consistently been linked with physical health (Rodin, 1986). People who report a subjective sense that they have greater control report better health, fewer and more minor symptoms, faster recovery from illness, and reduced mortality (Rodin, Timko, \& Harris, 1985). This association holds within income levels (Lachman \& Weaver, 1998), as individuals in low-income groups with a high sense of control appear to show levels of physical health comparable with those in higher-income groups. In addition, Bailis, Segall, Mahon, Chipperfield, and Dunn (2001) found that whereas perceived control was systematically related to socioeconomic differences in self-rated health status, this was not the direct result of greater participation in health-related behaviors on the part of those with higher perceived control. Thus, there is evidence that control over life may be an aspect of personality that directly explains at least part of the incomehealth gradient.

This would appear to result from the greater ability of people who perceive that they have control over life outcomes to exert that control over their income, placing perceived control in the role of a joint cause of both income and physical health outcomes. Perceived control would presumably affect income in two ways. First, the exertion of such control could result in the acquisition of both higher levels of education and better job opportunities with given educational credentials, and second, the exertion of such control could result in better ability to manage financial obligations within any given level of income.

\section{Our Assessment of These Constructs And Their RELATIONSHIPS}

This discussion of broadly construed constructs that have been proposed as causative agents in the relationship between income and physical health suggests that both the constructs and the instruments with which we can measure them are closely intertwined. We should expect scores on the measures to be strongly intercorrelated in most data sets that include measurements for all of them. Table 1 presents the correlations that we observed based on the twin sample of the MacArthur Foundation Survey of Midlife Development in the United States (MIDUS). The base sample consists of 998 twin pairs distributed roughly according to population throughout the continental United States and ranging in age from 25 to 74 . The sample and the way we have used it are described in greater detail by Johnson and Krueger (2003, 2004). For the work we have carried out to date, we have made use of the 719 same-sex 
Table 2. Correlation Matrix of Latent Variables Associated With Social Class Differences in Health

\begin{tabular}{lrrrrrr}
\hline \hline Variable & \multicolumn{1}{c}{1} & \multicolumn{1}{c}{2} & \multicolumn{1}{c}{3} & \multicolumn{1}{c}{4} & 5 & \multicolumn{1}{c}{6} \\
\hline 1. Health problems & 1.00 & -.37 & -.53 & -.21 & .62 & -.14 \\
2. Social relations & -.37 & 1.00 & .86 & .39 & -.59 & .17 \\
3. Attitude & -.53 & .86 & 1.00 & .77 & -.76 & .28 \\
4. Positive affect & -.21 & .39 & .77 & 1.00 & -.58 & .08 \\
5. Negative affect & .62 & -.59 & -.76 & -.58 & 1.00 & -.11 \\
6. Income & -.14 & .17 & .28 & .08 & -.11 & 1.00 \\
\hline
\end{tabular}

pairs (367 monozygotic, 352 dizygotic) for whom most of the data are available. For these twins, zygosity was determined using self-report questions regarding information such as similarity of eye and hair color and degree to which others were confused as to their identity during childhood. Such techniques are generally $>90 \%$ accurate (Christensen et al., 2003; Lykken, Bouchard, McGue, \& Tellegen, 1990), though 17 pairs in this sample were not considered classifiable on the basis of the self-reports. We have not made use of these pairs.

Purpose in life was measured using the three-item scale developed for telephone surveys and described by Ryff and Keyes (1995). Control, chronic illnesses, body mass index, and income were measured as described by Johnson and Krueger (2004). Extraversion and neuroticism, as trait-level manifestations of positive and negative affect, were measured based on Goldberg (1992), as reported by Lachman and Weaver (1997). Good mood and bad mood, as state-level manifestations of positive and negative affect, were measured as reported by Mroczek and Kolarz (1998), with adjustment for an additional item for each indicating the degree to which the emotions experienced in the last month were typical. Spouse, friend, and family relations were measured as reported by Whalen and Lachman (2000). The measure for twin relations included the same questions that we used here. For each social relations measure, the support and strain scales were combined (with the strain scale reversed) to obtain an overall measure of relationship quality.

As shown in Table 1, most of the correlations among the variables were significant at $p<.01$. The correlations of the two measures of negative affect with many of the other variables were particularly strong, though not as strong as the correlation between them (.54). Correlations of the two measures of positive affect with the other variables were generally lower, though still substantial. Control and purpose in life were significantly correlated as expected with all of the other variables. The only insignificant correlations were a few correlations involving income and body mass index, noteworthy possibly because they involved the only clearly objective measures but also because we tend to think that being rich and/ or thin will make us happy and fulfilled. The data, however, do not tend to support this (Lykken, 2000). To remove the effects of measurement error, we constructed latent variable (Joreskog \& Sorbom, 2002) correlations reflecting latent health problems (chronic illnesses and body mass index), social relations (relations with spouse, friends, family, and twin), attitude toward life (control and purpose), and positive (extraversion and good mood) and negative (neuroticism and bad mood) affect, leaving income as a single indicator. The model fit the data well (root mean square error of approximation $=.034$ ). The resulting latent variable correlations are shown in Table 2.
Table 3. Twin Correlations Among Variables Associated With Social Class Differences in Health

\begin{tabular}{lcccc}
\hline \hline Variable & $\begin{array}{c}\text { Monozygotic } \\
\text { Twins }\end{array}$ & $\begin{array}{c}\text { Dizygotic } \\
\text { Twins }\end{array}$ & $\begin{array}{c}\text { Indicated } \\
\text { Genetic } \\
\text { Influence }\end{array}$ & $\begin{array}{c}\text { Indicated } \\
\text { Shared } \\
\text { Environmental } \\
\text { Influence }\end{array}$ \\
\hline Purpose & .29 & .18 & .22 & .07 \\
Control & .33 & .28 & .10 & .23 \\
Spouse relations & .29 & -.03 & .58 & .00 \\
Friend relations & .22 & .09 & .26 & .00 \\
Family relations & .37 & .26 & .22 & .15 \\
Twin relations & .44 & .40 & .08 & .36 \\
Extraversion & .44 & .11 & .66 & .00 \\
Good mood & .41 & .20 & .42 & .00 \\
Neuroticism & .50 & .25 & .50 & .00 \\
Bad mood & .37 & .21 & .32 & .05 \\
Chronic illnesses & .43 & .19 & .48 & .00 \\
Body mass index & .73 & .40 & .66 & .07 \\
Income & .38 & .13 & .50 & .00 \\
\hline
\end{tabular}

Note: Indicated genetic and shared environmental influences were based on the Falconer formulas: $2\left(\mathrm{r}_{\mathrm{MZ}}-\mathrm{r}_{\mathrm{DZ}}\right)$ for genetic influences and $2 \mathrm{r}_{\mathrm{DZ}}-\mathrm{r}_{\mathrm{MZ}}$ for shared environmental influences. The twin correlations are double-entered Pearson approximations of intraclass correlations.

There were clear and strong relationships among most of these variables, but the strongest involved social relations and attitude, positive and negative affect and attitude, and social relations and negative affect. The weakest involved income, which is consistent with the idea that the association between physical health and income results from some additional variable(s) with causative influences on both.

\section{GENETIC AND ENVIRONMENTAL INFLUENCES UNDERLYING These Relationships}

\section{Basic Estimates of Genetic and}

Environmental Influences

Research using twin and adoption samples has consistently shown that about $50 \%$ of the variance in trait-level personality measures can be attributed to genetic influence (McGue, 2001). In addition, the environmental factors involved appear to be those that create differences among reared-together relatives rather than similarities. That is, in general, the environmental influences that make reared-together relatives similar (commonly termed "shared environmental influences") compose $<10 \%$ of the variance in trait-level personality measures. Among the variables we are considering here, we would expect that estimates such as these would apply to extraversion and neuroticism. State-level personality measures have most commonly been assessed using measures of negative mood or depression, and they generally show a lower level of genetic influence, on the order of $20-40 \%$, with about $10 \%$ shared environmental influence. Thus, they tend to show a higher level of nonshared environmental influence (including measurement error). This is likely due to the instability over time of such statelevel measurements (McGue \& Christensen, 2003). We would expect estimates such as these to apply to the measures we have termed good mood and bad mood. Table 3 shows the basic estimates from the MIDUS data. These estimates are generally consistent with the results of others presented above.

Genetic and environmental influences on variables involving perceived control have been less studied than other variables 
associated with personality, but estimates for such variables do exist. These estimates generally show somewhat lower genetic influences and slightly higher shared environmental influences, particularly for scales involving the perceived involvement of luck in personal outcomes (Johansson et al., 2001; Pedersen, Gatz, Plomin, Nesselroade, \& McClearn, 1989). As shown in Table 3, the MIDUS variables purpose and control are generally consistent with this, considering that most of the variable correlations in the table indicate no shared environmental influence at all. The presence of genetic influences on overall physical health as well as on specific diseases is well accepted (e.g., Komaroff, 1999), and the estimated $48 \%$ genetic influence on numbers of chronic illnesses shown in Table 3 for MIDUS would appear to be reasonable for a measure including a number of different conditions ranging from diabetes to persistent skin trouble. Genetic influences on body mass index are also well established (e.g., Carmichael \& McGue, 1995), and the estimates for MIDUS shown in Table 3 are again consistent. Genetic influences on income have also been consistently observed (Herrnstein \& Murray, 1994), though their interpretation is often controversial. The MIDUS data shown in Table 3 are, once more, in keeping with other estimates presented in the literature.

Genetic and environmental influences on social relations have been less studied, perhaps because, by their very nature, they involve variables beyond those associated with the traits of given individuals. But it is reasonable to think that each individual in a social relationship contributes to the quality of that relationship and that individuals tend to establish patterns of relationships over time. From this perspective, estimation of genetic and environmental influences on social relationships makes sense, and the data on social relations in MIDUS shown in Table 3 show an interesting pattern. For relations involving genetically unrelated others, the more intimate the relationship, the greater the genetic influence. For relations involving genetically related others, however, shared environmental influences were greater for presumably closer relationships (i.e., the co-twin) and apparent genetic influences were lower. One way to think about genetic and environmental influences on social relations is that the way the other person involved in any relationship approaches social relationships provides one of the primary sources of environmental influence on that relationship for the individual in question. To the extent that there are genetic influences on social relations, biological family members should be expected to approach them more similarly than do unrelated persons. Thus, for relationships involving genetically related others, the primary sources of environmental influences would come from people who approach social relationships similarly, for genetic as well as environmental reasons. Thus, one possible explanation for the pattern of data involving social relationships is that the estimates of shared environmental influence are capturing more than conventional shared environmental influences. That is, they may also be capturing the fact that biological family members share both environments and genes, inducing a correlation between shared environmental and genetic influences on social relationships. If not explicitly modeled, this kind of geneenvironment correlation will "show up" as shared environmental influence (Purcell, 2002). This serves to illustrate the point that genetic and environmental influences may not be so neatly separable.

\section{Beyond Basic Estimates of Genetic and Environmental Influences}

The information provided by estimates of genetic and environmental influences on behavioral variables is critical, as it makes clear that individuals bring important characteristics to the processes involved in the emergence of life outcomes. Such estimates are relatively uninformative, however, about the interplay in these processes between genetic and environmental influences that actually brings about the results. Genes and environments can interact $(\mathrm{G} \times \mathrm{E})$ with each other in the sense that genes may exert control over sensitivity to environments, or, equivalently, environmental circumstances may exert differential control over genetic effects (Kendler \& Eaves, 1986). An example would be increased antisocial behavior among genetically vulnerable individuals only when they experienced maltreatment during childhood (Caspi et al., 2002). Genes and environments can also be correlated ( $r_{\mathrm{GE}}$, expressed as a value between -1 and 1 in the manner usual to correlations) in the sense that genes may control exposure to different environments or, equivalently, that environments may control the frequency of occurrence of genes. Examples would be parents with mental illness who pass on to their children both the genes for vulnerability to mental illness and an unstable home environment (a so-called "passive" gene-environment correlation) or basketball camps in which the occurrence of genes for both height and athleticism is more frequent than in the overall population (a so-called "active" gene-environment correlation). This can take place because the same genetic influences are associated with both vulnerability to mental illness and provision of stability in the home environment or because the distinct genetic influences on the two characteristics tend to co-occur.

Most estimates of genetic and environmental influences are based on quantitative techniques that make no explicit provision for gene-environment correlations or interactions (e.g., the estimates in Table 3). At the same time, it is likely that such transactive effects involving complex traits are common. This does not, however, vitiate the straightforward sorts of estimates seen in Table 3 or in other studies. Rather, it highlights their potentially simplistic nature; they may apply only on an overall population level. This means that they can hide important patterns of underlying relationships in which genetic and environmental variances differ along other dimensions or within subgroups; that is, the genetic and environmental variances correlate or interact with each other. Because this can be expected to take place in systematic ways, it is possible to build provision for gene-environment correlations and interactions into our models to reveal the underlying patterns when we understand the nature of the population-level simplifications.

Without such provisions, correlation between genetic and shared environmental influences will tend to overstate estimates of shared environmental influence (consider this as a potential explanation of the estimates for social relationships in MIDUS described above), but correlation between genetic and nonshared environmental influences will tend to overstate estimates of genetic influence, as will interaction between genetic and shared environmental influences. On the other hand, again without such provisions, interaction between genetic and nonshared environmental influences will tend to overstate estimates of nonshared environmental influence (Purcell, 2002). 
In addition, when both $\mathrm{G} \times \mathrm{E}$ and $r_{\mathrm{GE}}$ involve the same environmental variable, the degree of $r_{\mathrm{GE}}$ will be conditional on the level of the environmental variable (Purcell, 2002). In circumstances such as those surrounding the social class-physical health gradient, where there is clear evidence for substantial genetic influence on all the variables involved and phenotypic (observable) correlations among them, multivariate genetic analyses that make provision for these kinds of genetic and environmental interplay can be crucial in illuminating the processes involved.

\section{Example of Interaction Involving the Income-Physical Health Gradient}

Using the MIDUS data, we recently demonstrated that both genetic variance and total variance associated with each of our two measures of physical health, number of chronic illnesses and body mass index, decreased both with increasing income and with increasing perceived control over life (Johnson \& Krueger, 2003, 2004). The effect on variance in health associated with income persisted when income was controlled for presence of health insurance and level of education. The decline in genetic variance in health measures with increasing income and perceived control implies the existence of $\mathrm{G} \times \mathrm{E}$ because the extent of genetic influence depends on individuals' environments. The decline in genetic variance associated with income was very substantial: Over income levels ranging from $2 S D$ below to $2 S D$ above the mean, genetic variance decreased by about two-thirds for both number of chronic illnesses and body mass index. The decline associated with perceived control was less dramatic though still significant: Over the same range of perceived control, genetic variance decreased by about onethird for chronic illnesses and one-half for body mass index.

These interactions took place in the presence of substantial $r_{\mathrm{GE}}$ as well, particularly those involving common genetic influences on perceived control and health. At the mean level of perceived control, $r_{\mathrm{GE}}$ was on the order of -.7 for both physical health measures. It remained relatively constant over the range of perceived control for chronic illnesses but increased to about -.9 at $1.5 S D$ above mean perceived control and decreased to about -.5 at $1.5 S D$ below for body mass index. At the mean level of income, $r_{\mathrm{GE}}$ was on the order of -.25 for both physical health measures. Again, it was relatively constant over the range of income for chronic illnesses but ranged from about -. 6 at $1.5 S D$ above mean income to about -.15 at $1.5 S D$ below for body mass index. The picture was complicated by the genetic correlation between income and perceived control. Though it was unimportant (.09) at the mean levels of both variables and ranged only from about -.3 to .3 over a $3-S D$ range of control, holding income constant, it ranged from .88 to -.01 over a similar range of income, holding control constant.

These results suggest an intricate interplay among the genetic and environmental influences on the three variables, in which perceived control and/or economic resources contribute to one's ability to manage one's life situation to minimize one's vulnerabilities to genetically influenced disease. At the same time, common sets of genetic influences contribute both to higher income and better physical health and to higher perceived control and better physical health. These relationships could result directly from the experience of greater physical health (e.g., healthy people are less likely to miss work and more likely to be able to carry out their jobs with energy and competence, which may lead, over time, to higher income). Of course they could also result from the experience of higher income or perceived control. In any event, all the variables appear to be more closely intertwined in higher-income environments. A working model for how these variables transact might be that the effects of genetic vulnerabilities are minimized and genetic strengths consolidated in favorable environments at the same time that genetic vulnerabilities are compounded and genetic strengths isolated in unfavorable ones.

\section{Genetic and Environmental Influences on and Correlations Among the Variables Associated With the Income-Physical Health Gradient}

To explore the genetic and environmental links among the variables discussed above associated with the income-physical health gradient, we estimated the genetic and environmental overall population-level correlations among the MIDUS measures. That is, we estimated the extent to which genetic and environmental influences were common to pairs of variables (expressed as values between -1 and 1 in the manner usual to correlations). These correlations are independent both of the phenotypic (observable) correlations and of the proportions of genetic and environmental influences on the two traits. That is, genetic influences on two traits may be common or independent whether total genetic influences on either trait are great or small, and the same is true for common environmental influences. At the same time, genetic influences on two traits may be common or independent whether the observed correlation between the two traits is great or small, and the same is true for environmental correlations. When the observed correlation between two variables is high, however, either genetic or environmental correlations will generally be high or both. The genetic and environmental correlations may also often be correlated (Hegmann \& DeFries, 1970), though this is not necessarily the case (Searle, 1961).

To estimate the genetic and environmental correlations in our data, we used mean values of the standardized age- and sexadjusted scores on the related variables to create composite scores to approximate latent versions of these variables. Thus, we averaged adjusted standardized scores for number of chronic illnesses and body mass index to get a composite health problems score, scores for the four categories of social relations to get a composite social relations score, scores for perceived control and purpose to get a composite attitude score, scores for neuroticism and bad mood to get a negative affect score, and scores for extraversion and good mood to get a positive affect score. There are other more sophisticated ways that it may make sense to treat these variables, but this approach should be sufficient to gain an initial impression of the underlying relationships. The results are shown in Table 4.

There were substantive and significant genetic correlations between social relations and attitude (.83), social relations and positive affect (.51), positive affect and attitude (.75), and positive and negative affect $(-.73)$ as well as shared environmental correlations between negative affect and social relations (-.99), negative affect and attitude (-.66), and social relations and attitude (.59). Estimates of genetic and environmental correlations have large standard errors (Carey \& DiLalla, 1994), however, so the confidence intervals associated with our 
Table 4. Genetic, Shared, and Nonshared Environmental Correlations Among Variables Associated With Social Class Differences in Health

\begin{tabular}{lcccccc}
\hline \hline Variable & 1 & 2 & 3 & 4 & 5 & 6 \\
\hline Genetic & & & & & & \\
1. Health problems & 1.00 & $-.34^{*}$ & -.28 & $-.35^{* *}$ & $.31^{*}$ & -.21 \\
2. Social relations & $-.34^{*}$ & 1.00 & $.83^{* *}$ & $.51^{* *}$ & -.06 & .21 \\
3. Attitude & -.28 & $.83^{* *}$ & 1.00 & $.75^{* *}$ & $-.56^{*}$ & .12 \\
4. Positive affect & $-.35^{* *}$ & $.51^{* *}$ & $.75^{* *}$ & 1.00 & $-.73^{* *}$ & .07 \\
5. Negative affect & $.31^{*}$ & -.06 & $-.56^{*}$ & $-.73^{* *}$ & 1.00 & -.14 \\
6. Income & -.21 & .21 & .12 & .07 & -.14 & 1.00 \\
Shared environmental & & & & & & \\
1. Health problems & 1.00 & $-.55^{*}$ & $-.53^{*}$ & .25 & $.46^{*}$ & $-.79^{*}$ \\
2. Social relations & $-.55^{*}$ & 1.00 & $.59^{* *}$ & .19 & $-.99^{* *}$ & $.66^{*}$ \\
3. Attitude & $-.53^{*}$ & $.59^{* *}$ & 1.00 & .69 & $-.66^{* *}$ & $.94^{*}$ \\
4. Positive affect & .25 & .19 & .69 & 1.00 & -.34 & .40 \\
5. Negative affect & $.46^{*}$ & $-.99^{* *}$ & $-.66^{* *}$ & -.34 & 1.00 & $-.67^{*}$ \\
6. Income & $-.79^{*}$ & $.66^{*}$ & $.94^{*}$ & .40 & $-.67^{*}$ & 1.00 \\
Nonshared environmental & & & & & & \\
1. Health problems & 1.00 & -.03 & $-.13^{* *}$ & $-.12^{* *}$ & $.27^{* *}$ & .03 \\
2. Social relations & -.03 & 1.00 & $.20^{* *}$ & $.25^{* *}$ & $-.34^{* *}$ & .00 \\
3. Attitude & $-.13^{* *}$ & $.20^{* *}$ & 1.00 & $.22^{* *}$ & $-.32^{* *}$ & $.14^{* *}$ \\
4. Positive affect & $-.12^{* *}$ & $.25^{* *}$ & $.22^{* *}$ & 1.00 & $-.39^{* *}$ & .05 \\
5. Negative affect & $.27^{* *}$ & $-.34^{* *}$ & $-.32^{* *}$ & $-.39^{* *}$ & 1.00 & -.01 \\
6. Income & .03 & .00 & $.14^{* *}$ & .05 & -.01 & 1.00 \\
\hline
\end{tabular}

${ }^{*}$ Correlations were significant at $p<.20 .{ }^{* *}$ Correlations were significant at $p<.05$. Unstarred correlations were insignificant even at $p=.20$.

estimates were wide and many of the correlations were not significant even though they appeared substantive. Confidence intervals around correlations of this type are particularly wide when the source of influence accounts for little variance. For reference, the proportions of variance associated with each variable are shown in Table 5. The proportions were relatively small for genetic influence on attitude, social relations, and negative affect and for all of the shared environmental influences. The small proportions of variance attributable to shared environmental influences relative to nonshared environmental influences were part of the reason why only three shared environmental correlations were significant at the conventional level of $p<.05$, yet most of the nonshared environmental correlations were significant even when they were not very substantive.

In addition, no genetic correlation involving income was significant at $p<.05$, and the only genetic correlation involving health problems that was significant at that level was -.35 with positive affect. To explore the possible interrelationships on a more liberal basis, we also examined correlations that were significant at $p<.20$. At the genetic level, this added possible moderate correlations between negative affect and attitude, negative affect and health problems, and social relations and health problems. At the shared environmental level, this added intriguing possible relationships involving both health problems and income and the other variables except for positive affect.

Another way to consider the relationships among these variables is to examine the proportions of the phenotypic (observed) correlations that can be attributed to genetic and environmental influences common to the two variables. These proportions are sometimes called bivariate genetic and
Table 5. Estimated Proportions of Genetic and Environmental Influence

\begin{tabular}{lccc}
\hline \hline & & \multicolumn{2}{c}{ Environmental } \\
\cline { 3 - 4 } Variable & Genetic & Shared & Nonshared \\
\hline Health problems & .42 & .14 & .44 \\
Social relations & .21 & .28 & .52 \\
Attitude & .14 & .23 & .63 \\
Positive affect & .48 & .01 & .51 \\
Negative affect & .24 & .21 & .55 \\
Income & .33 & .05 & .62 \\
\hline
\end{tabular}

environmental influences. Like genetic and environmental correlations, bivariate genetic and environmental influences are independent both of the phenotypic (observable) correlations and of the proportions of genetic and environmental influences on the two traits. That is, bivariate genetic influences on two traits may be great or small whether total genetic influences on either trait are great or small, and the same is true for common environmental influences. At the same time, bivariate genetic influences on two traits can be great or small whether the observed correlation between the two traits is great or small, and the same is true for environmental correlations. Bivariate genetic and environmental influences differ from genetic and environmental correlations, however, in that there is an inverse relationship between bivariate genetic and environmental influences on a trait, and high phenotypic correlations imply nothing about likely magnitude of either bivariate genetic or environmental influences. The estimated bivariate genetic and environmental influences on the phenotypic correlations among the MIDUS variables associated with social class differences in health are shown in Table 6. The bivariate genetic influences linking health problems and each of the other variables were interesting. Though many of the

Table 6. Bivariate Genetic and Environmental Influences on Correlations Among Variables Associated With Social Class Differences in Health

\begin{tabular}{|c|c|c|c|c|c|c|}
\hline Variable & 1 & 2 & 3 & 4 & 5 & 6 \\
\hline \multicolumn{7}{|l|}{ Genetic } \\
\hline 1. Health problems & & .64 & .40 & .73 & .37 & .88 \\
\hline 2. Social relations & .64 & & .22 & .32 & .02 & .34 \\
\hline 3. Attitude & .40 & .22 & & .25 & .09 & .05 \\
\hline 4. Positive affect & .73 & .32 & .25 & & .52 & .49 \\
\hline 5. Negative affect & .37 & .02 & .09 & .52 & & .35 \\
\hline 6. Income & .88 & .34 & .05 & .49 & .35 & \\
\hline \multicolumn{7}{|l|}{ Shared environmental } \\
\hline 1. Health problems & & .25 & .20 & -.01 & .10 & .27 \\
\hline 2. Social relations & .25 & & .32 & .02 & .41 & .69 \\
\hline 3. Attitude & .20 & .32 & & .06 & .20 & .30 \\
\hline 4. Positive affect & -.01 & .02 & .06 & & .00 & .00 \\
\hline 5. Negative affect & .10 & .41 & .20 & .00 & & .56 \\
\hline 6. Income & .27 & .69 & .30 & .00 & .56 & \\
\hline \multicolumn{7}{|l|}{ Nonshared environmental } \\
\hline 1. Health problems & & .11 & .40 & .28 & .53 & -.17 \\
\hline 2. Social relations & .11 & & .46 & .66 & .57 & -.03 \\
\hline 3. Attitude & .40 & .46 & & .69 & .71 & .65 \\
\hline 4. Positive affect & .28 & .66 & .69 & & .48 & .51 \\
\hline 5. Negative affect & .53 & .57 & .71 & .48 & & .09 \\
\hline 6. Income & -.17 & -.03 & .65 & .51 & .09 & \\
\hline
\end{tabular}




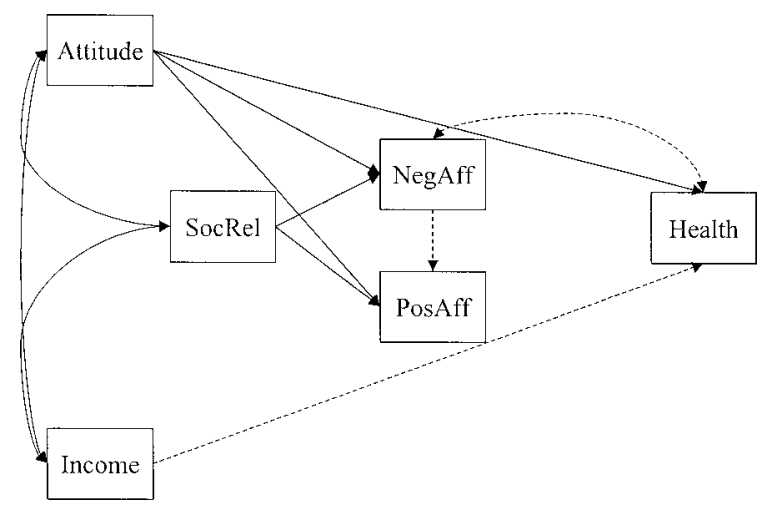

Figure 1. Social relations model of causal relations among variables associated with social class differences in health. $\chi^{2}=235.83, d f=3$, $p<.00001$. Dotted lines indicate paths we added to the basic model to improve model fit. All paths shown were significant, and no additional paths were significant. PosAff $=$ positive affect; SocRel $=$ social relations; $\mathrm{NegAff}=$ negative affect.

phenotypic correlations between these variables were quite small, the genetic influences on these correlations were substantial, suggesting strong genetic mediation of the relationships. The bivariate genetic influence $(.88)$ on the correlation between health problems and income ( -.14 from Table 2 ) was particularly noteworthy. What this means is that though the phenotypic correlation between health problems and income was modest, that modest correlation was almost completely accounted for by genetic influences common to health problems and income.

\section{Models Testing Direction of Causation}

The method of path analysis, developed by Wright (1934), can be used to test the plausibility of potential causal relationships among variables in nonexperimental conditions. The technique can be used with phenotypic relationships, of course, but the ability to decompose genetic and environmental components of variance can add considerable explanatory power if sample sizes are large enough and measurements are sufficiently valid and precise. There are several ways in which data involving genetic and environmental influences can be used in such models. Carey and DiLalla (1994) provided an example using twin phenotypic variances and covariances to test several plausible models of how genetic influences might link personality and psychopathology. Here, we take a different approach, using the matrix of genetic variances and covariances from the MIDUS variables associated with income-related differences in health to investigate possible underlying causal relationships. This approach can be particularly informative because though environmental circumstances can occasionally modulate genetic expression (e.g., Rutherford, 2000), the environment does not, in general, modify the genotype (environmentally induced mutation being an example of an exception), making inferences about the causative nature of genetic influences more certain (Plomin $\&$ Spinath, 2004). Such inferences would appear to be especially relevant in the presence of high bivariate genetic influences such as those we observed here.

The genetic correlations in Table 4 seem consistent with two models that have been suggested to explain social class

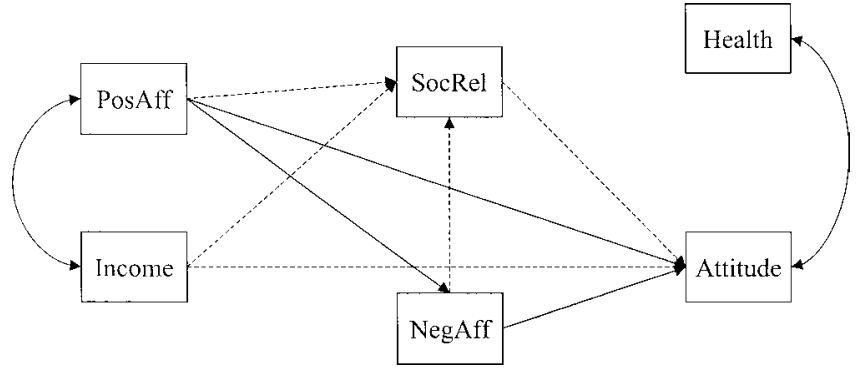

Figure 2. Positive affect model of causal relations among variables associated with social class differences in health. $\chi^{2}=14.66, d f=4$, $p=.0055$. Dotted lines indicate paths we added to the basic model to improve model fit. All paths shown were significant, and no additional paths were significant. PosAff $=$ positive affect; SocRel $=$ social relations; $\operatorname{NegAff}=$ negative affect.

differences in health. The first, which we term Model 1, places attitude and social relationships in the causal roles (e.g., Cohen $\&$ Wills, 1985), with social relationships predicting the direct influence of attitude on health problems and attitude's indirect influences on health problems via positive and negative affect, as shown in Figure 1. The second, which we term Model 2, places positive affect in the causal role (e.g., Frederickson \& Levenson, 1998), with indirect effects on health problems via negative affect and attitude, as shown in Figure 2. We fit these models to the genetic variance-covariance matrix from the MIDUS data, adding the paths shown with dotted lines in response to the modification indexes in the initial model fits. We tested the direction of effects carefully: In all cases, there were significant deteriorations in model fit when the directions of effect were reversed, and adding the reciprocal path did not significantly improve model fit. The models are specified in a somewhat simplistic manner, for example, without provision for reciprocal effects from negative affect or health problems to income, but they were intended as preliminary investigations of physical health problems as the outcome variable.

The results of fitting these models were dramatic. Model 1 fit poorly $\left(\chi^{2}=235.83,3 d f, p<.00001\right)$. Model 2 , however, fit much better $\left(\chi^{2}=14.66,4 d f, p=.0055\right)$. This model had several interesting features that seem consistent both with the findings of others and with our results showing decreased genetic variance in high-income and high-control environments. There was a reciprocal relationship between attitude and health. Negative affect did not contribute directly to health problems (consistent with Watson \& Pennebaker [1989]) but did contribute indirectly via attitude (consistent with Gallo \& Mathews [2003]). Income did not contribute directly to health problems either but did contribute indirectly via attitude (again consistent with Gallo \& Mathews [2003]). Social relations did not contribute to health directly but did indirectly via attitude. This is a more surprising finding but seems consistent with the observation of Brown and colleagues (2003) that receiving social support conferred no health benefit after controlling for the effect of giving support. It deserves further investigation. Attitude's links with most of the other variables would appear to place it in a good position both to exert a buffering effect on genetic expression (Rutherford, 2000) of the kind that would be necessary to explain the interaction effect we observed 
previously (Johnson \& Krueger, 2004) and to draw in relationships among the other variables as well. Income's influence on attitude places it in a position to exert a similar effect, consistent with Johnson and Krueger (2003).

\section{IMPLICATIONS OF GENE-ENVIRONMENT INTERPLAY ON Causative Agents}

The above discussion should make clear the potential for sophisticated multivariate analyses of genetic and environmental influences to illuminate the processes involved in incomerelated differences in health as well as providing fertile ground for developing testable new hypotheses. The value is not limited simply to understanding income-related differences in health, of course, but we have featured it in our discussion because of our own work in the area and because of its obvious relevance to an aging population. The potential of behavior genetics for illuminating complex dynamic processes may be surprising, because we are accustomed to thinking of individual genetic differences translating directly into individual phenotypic differences. There is little question that many genetic effects operate in this fashion, but we think of these effects as normative primarily because they are the most obvious and therefore have been the easiest to come to understand (Rutherford, 2000). Thus, the hypothesis that one gene produces one enzyme that has one function has led to the commonly held notion that genes can be understood in isolation, have particular dominant or recessive characteristics, produce unambiguous phenotypic effects, and govern development in an explicit and deterministic manner.

This has led many to see estimation of genetic influence as of limited value in understanding dynamic processes. Current molecular genetic research, however, is revealing repeatedly that even apparently critical components governing clearly essential processes can be disrupted in some circumstances without major phenotypic consequences. At the same time, in other circumstances, such disruptions may produce the expected severe consequences. For example, in D. melanogaster, mutations of the ey form in the ey/Pax-6 gene cause dramatic reductions or total loss of the eye in some contexts, but in other combinations of genetic background and environmental (temperature, humidity, nutrition) conditions, normal eye development occurs even in these mutants (Morgan, 1929). The reverse is also true: Genetic expression may be buffered in some environmental circumstances but manifested in others. In another example from D. melanogaster, Waddington (1957) demonstrated that a 4-hour heat pulse delivered at 21-23 hours of pupal development causes a disruption of posterior crossveins in a few flies. The disrupted phenotype could be shown to result from the interaction of polygenic determinants with the "stressful environment" by cross-breeding those that manifested the effect and repeating the stress on the progeny. The fraction of affected animals increased each generation until most produced the disrupted phenotype. Not only that, but some fraction of untreated control flies from the selection lines also expressed the disrupted phenotype, even in the absence of the stressful heat pulse. Effects such as these, at several different levels, may underlie social class differences in physical health, a population-level association. Such effects are also likely involved in the impact of aging on the physical health of the individual, and these effects may be manifested very differently in individuals with different characteristics. For example, about $10 \%$ of Caucasians carry a gene $(C Y P 1 A 1)$ for an enzyme that catalyzes deleterious metabolism of a diverse array of endogenous and exogenous chemicals ranging from hormones to pollutants. The enzyme is associated with increased risk over time of lung cancer in smokers (and not in nonsmokers), but the increase in risk is much more dramatic in light smokers than in heavy smokers (Perera, 1997). In other words, the presence of the gene alters the usual relationships among duration and quantity of exposure, aging, and incidence of disease. To the extent that such effects operate, it is likely that analyses explicitly recognizing the interplay among genetic and environmental influences will prove to be essential to the development of further understanding. One strength of MIDUS is that it is in the process of administering a follow-up wave of data collection. It should thus be possible before long to investigate some of the possible ways that aging transacts with the other variables involved in the association between physical health and income and, more broadly, social class.

Investigations of environmental buffering effects on genetic expression are relatively recent. Several have been published to date, however, involving, in addition to physical health (Johnson \& Krueger, 2003, 2004), genetically influenced behaviors including disinhibition (e.g., Boomsma, Geus, de Baal, \& van Koopmans, 1999), adolescent alcohol use (e.g., Heath et al., 1999), depression (e.g., Caspi et al., 2003), and intelligence (Turkheimer, Haley, Waldron, D'Onofrio, \& Gottesman, 2003), among others. There appears to be a pattern common to the findings in these studies that leads to a testable hypothesis that would be of predictive value: When a trait is adaptive and genetic expression is environmentally malleable, genetic expression is buffered in more difficult, stressful environments, leading to greater observed genetic variance in more favorable, less stressful environments. When a trait is maladaptive and genetic expression is environmentally malleable, genetic variance is buffered in more favorable, less stressful environments, leading to greater observed genetic variance in more difficult, stressful environments. The key to testing this hypothesis and making predictions based on it will be to identify the circumstances in which genetic effects are environmentally malleable.

\section{Where do We Go From Here?}

The models we have presented here should be viewed as preliminary indications of causal processes, for several reasons. First, though we made use of variables based on wellestablished scales in common use in research of this type, in many cases the scales were shortened in MIDUS because of the extensive volume of data collected in the study. Second, the variables were all based on self-reports and were therefore subject to the well-known biases associated with such measures, particularly those involving trait-level negative affect when evaluating health-related variables (Watson \& Pennebaker, 1989). Third, we simply formed composites of related variables in order to develop straightforward models to demonstrate methodologic potential and generate hypotheses for further evaluation. The concepts involved deserve much more precise measurement and sophisticated treatment as well as more stringent model development and hypothesis testing. In addition, we think it likely that a critical variable, general 
intelligence, has been omitted from most of the discussion of income-related differences in physical health over the years.

General intelligence could potentially serve as a common cause for both income and physical health. Lubinski and Humphreys (1997) have demonstrated convincingly that general intelligence (or lack thereof) contributes significantly to membership in groups at high risk for certain adverse health outcomes including AIDS, lung cancer, and low infant birth weight. At the same time, general intelligence contributes significantly to membership in groups at risk for adverse social outcomes, including poverty. Deary and colleagues (Deary, Whalley, \& Starr, 2003; Deary, Whiteman, Starr, Whalley, \& Fox, 2004) have provided much more direct evidence: In two Scottish population cohorts, lower general intelligence measured at age 11 predicted increased death rates in adulthood overall as well as from stomach and lung cancers and heart disease specifically. It also predicted increased number of hospital discharges.

Gottfredson (2004) has carried the causal argument further. She cited the extensive findings that general intelligence is a heritable characteristic not permanently influenced by family advantage that contributes directly to social and economic success as well as to pathology in adulthood. At the same time, she compiled an impressive array of evidence that indicators of general intelligence are related to health knowledge, health behavior (including both prevention and maintenance activities), accident prevention, and thus to health itself. She noted, however, that data relating general intelligence directly to health are relatively scarce, for two reasons. First, scores on mental tests that have been administered for other reasons are not generally readily available to researchers, and second, most health-related research studies have not included measures of mental ability. This is true of MIDUS to date (though the follow-up assessment includes a cognitive battery), so we have been unable to investigate directly the effects of general intelligence. We note, however, that the interrelationships suggested by the MIDUS data presented here may be complicated by the potential for a genetically influenced trait that we have not measured, such as general intelligence, to act to correlate genetic and environmental influences underlying the variables that we have measured. We believe that including some measure of general intelligence in future health-related studies is of critical importance.

\section{ACKNOWLEDGMENTS}

This research was supported by the John D. and Catherine T. MacArthur Foundation Research Network on Successful Midlife Development and by National Institute on Aging Grant AG20166.

Address correspondence to Wendy Johnson or Robert Krueger, Department of Psychology, 75 E. River Rd., Minneapolis, MN 55455. E-mails: john4350@tc.umn.edu; krueg038@tc.umn.edu

\section{REFERENCES}

Adler, N. E., Boyce, T., Chesney, M. A., Cohen, S., Folkman, S., Kahn, R. L., et al. (1994). Socioeconomic status and health. American Psychologist, 49, 15-24.

Adler, N. E., Epel, E. S., Castellazzo, G., \& Ickovics, J. R. (2000). Relationship of subjective social and objective social status with psychological and physiological functioning: Preliminary data in healthy white women. Health Psychology, 79, 586-592.

Adler, N. E., \& Snibbe, A. C. (2003). The role of psychosocial processes in explaining the gradient between socioeconomic status and health. Current Directions in Psychological Science, 12, 119-123.
Bailis, D. S., Segall, A., Mahon, M. J., Chipperfield, J. G., \& Dunn, E. M. (2001). Perceived control in relation to socioeconomic and behavioral resources for health. Social Science and Medicine, 52, 1661-1676.

Beiser, M. (1974). Components and correlates of social behavior. Journal of Health and Social Behavior, 15, 320-327.

Berkman, L. F., \& Breslow, L. (1983). Health and ways of living. New York: Oxford University Press.

Berkman, L. F., \& Syme, L. F. (1979). Social networks, host resistance, and mortality: A nine-year follow-up study of Alameda County residents. American Journal of Epidemiology, 100, 186-204.

Boomsma, D. I., Geus, E. J. C., de Baal, G. C. M., \& van Koopmans, J. R. (1999). A religious upbringing reduces the influence of genetic factors on disinhibition: Evidence for interaction between genotype and environment on personality. Twin Research, 2, 115-125.

Brown, S. L., Nesse, R. M., Vinokur, A. D., \& Smith, D. M. (2003). Providing social support may be more beneficial than receiving it: Results from a prospective study of mortality. Psychological Science, $14,320-327$.

Carey, G., \& DiLalla, D. L. (1994). Personality and psychopathology: Genetic perspectives. Journal of Abnormal Psychology, 103, 32-43.

Carmichael, C., \& McGue, M. (1995). A cross-sectional examination of height, weight, and body mass index in adult twins. Journal of Gerontology: Biological Sciences, 50A, B237-B244.

Caspi, A., McClay, J., Moffitt, T., Mill, J., Martin, J., Craig, I. W., et al. (2002). Role of genotype in the cycle of violence in maltreated children. Science, 297, 752-754.

Caspi, A., Sugden, K., Moffitt, T., Taylor, A., Craig, I. W., Harrington, H., et al. (2003). Influence of life stress on depression: Moderation by a polymorphism in the 5-HTT gene. Science, 301, 386-389.

Christensen, L., Frederiksen, H., Schousboe, K., Skytthe, A., von WurmbSchwark, N., Christensen, K., et al. (2003). Age and sex differences in the validity of questionnaire-based zygosity in twins. Twin Research, 6, 275-278.

Cohen, S. (1988). Psychosocial models of the role of social support in the etiology of physical disease. Health Psychology, 7, 269-297.

Cohen, S., \& Wills, T. A. (1985). Stress, social support, and the buffering hypothesis. Psychological Bulletin, 98, 310-357.

Costa, P. T., \& McCrae, R. R. (1992). The revised NEO Personality Inventory (NEO-PI-R) and the NEO Five-Factor Inventory (NEO-FFI) professional manual. Odessa, FL: Psychological Assessment Resources.

Cramer, J. C. (1995). Racial and ethnic differences in birthweight: The role of income and financial assistance. Demography, 32, 231-247.

Deary, I. J., Whalley, L. J., \& Starr, J. M. (2003). IQ at age 11 and longevity: Results of a follow up of the Scottish Mental Survey, 1932. In C. Finch, J.-M. Robine, \& Y. Christen (Eds.), Brain and longevity: Perspectives and longevity (pp. 153-164). Berlin: Springer.

Deary, I. J., Whiteman, M. C., Starr, J. M., Whalley, L. J., \& Fox, H. C. (2004). The impact of childhood intelligence on later life: Following up the Scottish Mental Surveys of 1932 and 1947. Journal of Personality and Social Psychology, 86, 130-147.

Diefenbach, M., Leventhal, E. A., Leventhal, H., \& Patrick-Miller, L. (1996). Negative affect relates to cross-sectional but not longitudinal symptom reporting: Data from elderly adults. Health Psychology, 15, 282-288.

Dua, J. K. (1993). The role of negative affect and positive affect in stress, depression, self-esteem, assertiveness, Type A behaviors, psychological health, and physical health. Genetic, Social, and General Psychology Monographs, 119, 515-552.

Frederickson, B. L., \& Levenson, R. W. (1998). Positive emotions speed recovery from the cardiovascular sequelae of negative emotions. Cognition and Emotion, 12, 191-220.

Gallo, L. C., \& Mathews, K. A. (2003). Understanding the association between socioeconomic status and physical health: Do negative emotions play a role? Psychological Bulletin, 129, 10-51.

Goldberg, L. R. (1992). The development of markers for the Big-Five factor structure. Psychological Assessment, 4, 26-42.

Gottfredson, L. S. (2004). Intelligence: Is it the epidemiologists' elusive "fundamental cause" of social class inequalities in health? Journal of Personality and Social Psychology, 86, 174-199.

Haan, M., Kaplan, G., \& Syme, S. L. (1989). Socioeconomic status and health: Old observations and new thoughts. In J. D. Bunker \& B. G. B. Kehrer (Eds.), Pathways to health: The role of social factors (pp. 76135). Menlo Park, CA: Henry J. Kaiser Family Foundation. 
Heath, A. C., Madden, P. A. F., Grant, J. D., McLaughlin, T. L., Todorov, A. A., \& Bucholz, K. K. (1999). Resiliency factors protecting against teenage alcohol use and smoking: Influences of religion, religious involvement and values, and ethnicity in the Missouri Adolescent Female Twin Study. Twin Research, 2, 145-155.

Hegmann, J. P., \& DeFries, J. C. (1970). Are genetic correlations and environmental correlations correlated? Nature, 226, 284-285.

Herrnstein, R. J., \& Murray, C. (1994). The bell curve: Intelligence and class structure in American life. New York: Free Press.

House, J. S., Landis, K. R., \& Umberson, D. (1988). Social relationships and health. Science, 241, 540-545.

Johansson, B., Grant, J. D., Plomin, R., Pedersen, N., Ahern, F., Berg, S., et al. (2001). Health locus of control in late life: A study of genetic and environmental influences in twins aged 80 years and older. Health Psychology, 20, 33-40.

Johnson, W., \& Krueger, R. F. (2003). Genetic effects on physical health: Lower at higher income levels. Behavior Genetics (submitted).

Johnson, W., \& Krueger, R. F. (2004). Higher perceived life control decreases genetic variance in physical health: Evidence from a National Twin Study. Journal of Personality and Social Psychology (in press).

Joreskog, K., \& Sorbom, D. (2002). LISREL 8.53: User's reference guide. Chicago: Scientific Software International.

Judge, T. A., Erez, A., \& Thoresen, C. J. (2000). Why negative affectivity (and self-deception) should be included in job stress research: Bathing the baby with the bath water. Journal of Organizational Behavior, 21, $101-111$.

Kahn, J. K., Hessling, R. M., \& Russell, D. W. (2003). Social support, health, and well-being among the elderly: What is the role of negative affectivity? Personality and Individual Differences, 35, 5-17.

Kendler, K. S., \& Eaves, L. (1986). Models for the joint effect of genotype and environment on liability to psychiatric illness. American Journal of Psychiatry, 143, 279-289.

Komaroff, A. L. (Ed.). (1999). Harvard Medical School family medical guide. New York: Simon \& Schuster.

Lachman, M. E., \& Weaver, S. L. (1997). The Midlife Development Inventory (MIDI) personality scales: Scale construction and scoring. Waltham, MA.

Lachman, M. E., \& Weaver, S. L. (1998). The sense of control as a moderator of social class differences in health and well-being. Journal of Personality and Social Psychology, 74, 763-773.

Langer, E. J. (1989). Mindfulness. Cambridge, MA: Addison-Wesley.

Leventhal, E. A., Hansell, S., Diefenbach, M., Leventhal, H., \& Glass, D. C. (1996). Negative affect and self-report of physical symptoms: Two longitudinal studies of older adults. Health Psychology, 15, 193-199.

Levy, S. M., Herberman, R. B., Maluish, A. M., Schlien, B., \& Lippman, M. (1985). Prognostic risk assessment in primary breast cancer behavioral and immunological parameters. Health Psychology, 4, 99-113.

Lu, L., \& Argyle, M. (1992). Receiving and giving support: Effects on relationships and well-being. Counseling Psychology Quarterly, 5, 123-133.

Lubinski, D., \& Humphreys, L. G. (1997). Incorporating general intelligence into epidemiology and the social sciences. Intelligence, 24, 159-201.

Lykken, D. T. (2000). Happiness: What studies on twins show us about nature, nurture, and the happiness set-point. New York: Golden Books.

Lykken, D. T., Bouchard, T. J., McGue, M., \& Tellegen, A. (1990). The Minnesota Twin Family Registry: Some initial findings. Acta Genetica Medica Gemellol, 39, 35-70.

Maddi, S., \& Khoshaba, D. M. (1994). Hardiness and mental health. Journal of Personality Assessment, 63, 265-274.

McEwen, B. S. (1998). Protective and damaging effects of stress mediators. New England Journal of Medicine, 338, 171-179.

McGue, M. (2001). Genetics of personality. In D. L. Rimoin, J. M. Connor, R. E. Pyeritz, \& B. R. Korf (Eds.), Emery and Rimoin's principles and practice of medical genetics (4th ed., pp. 2791-2800). London: Churchill Livingstone.

McGue, M., \& Christensen, K. (2003). The heritability of depression symptoms in elderly Danish twins: Occasion-specific versus general effects. Behavior Genetics, 33, 83-93.

Morgan, T. H. (1929). Variability of eyeless. Publication of the Carnegie Institution, 399, 139-168.

Mroczek, D., \& Kolarz, D. (1998). The effect of age on positive and negative affect. Journal of Personality and Social Psychology, 75, 1333-1349.

Parsons, P. A. (2002). Aging: The fitness-stress continuum and genetic variability. Experimental Aging Research, 28, 347-359.

Parsons, P. A. (2003). From the stress theory of aging to energetic and evolutionary expectations for longevity. Biogerontology, 4, 63-73.

Pedersen, N., Gatz, M., Plomin, R., Nesselroade, J. R., \& McClearn, G. E. (1989). Individual differences in locus of control during the second half of the life span for identical and fraternal twins reared apart and together. Journal of Gerontology, 44, 100-105.

Pennebaker, J. W. (1990). Opening up: The healing power of confiding in others. New York: William Morrow.

Pennebaker, J. W., Czajka, J. A., Cropanzano, R., \& Richards, B. C. (1990). Levels of thinking. Personality and Social Psychology Bulletin, 16, 743-757.

Pennebaker, J. W., Hughes, C., \& O'Heeron, R. C. (1987). The psychophysiology of confession: Linking inhibitory and psychosomatic processes. Journal of Personality and Social Psychology, 52, 781-793.

Perera, F. P. (1997). Environment and cancer: Who are susceptible? Science, 278, 1068-1073.

Plomin, R., \& Spinath, F. (2004). Intelligence: Genetics, genes, and genomics. Journal of Personality and Social Psychology, 86, 112-129.

Purcell, S. (2002). Variance component models for gene-environment interaction in twin analysis. Twin Research, 5, 554-571.

Rodin, J. (1986). Aging and health: Effects of the sense of control. Science, $233,1271-1276$.

Rodin, J., Timko, C., \& Harris, S. (1985). The construct of control: Biological and psychosocial correlates. In C. Eisdorfer, M. P. Lawton, \& G. L. Maddox (Eds.), Annual review of gerontology and geriatrics (pp. 3-55). New York: Springer.

Rutherford, S. L. (2000). From genotype to phenotype: Buffering mechanisms and the storage of genetic information. BioEssays, 22, $1095-1105$.

Ryff, C. D., \& Keyes, C. L. M. (1995). The structure of psychological well-being revisited. Journal of Personality and Social Psychology, 69, 719-727.

Ryff, C. D., \& Singer, B. (2001). Emotion, social relationships, and health. New York: Oxford University Press.

Schier, M. F., \& Carver, C. S. (1987). Dispositional optimism and physical well-being: The influence of generalized outcome expectancies on health. Journal of Personality, 55, 169-210.

Searle, S. R. (1961). Phenotypic, genetic and environmental correlations. Biometrics, 17, 474-480.

Smith, C., Fernengel, K., Holcroft, C., Gerald, K., \& Marien, L. (1994). Meta-analysis of the associations between social support and health outcomes. Annals of Behavioral Medicine, 16, 352-362.

Steenland, K., Henley, J., \& Thun, M. (2002). All-cause and cause-specific death rates by educational status for two million people in two American Cancer Society cohorts. American Journal of Epidemiology, $156,11-21$.

Tellegen, A. (in press). Manual for the Multidimensional Personality Questionnaire. Minneapolis.

Turkheimer, E., Haley, A., Waldron, M., D’Onofrio, B., \& Gottesman, I. I. (2003). Socioeconomic status modifies heritability of IQ in young children. Psychological Science, 14, 623-628.

Waddington, C. H. (1957). The strategy of the genes. New York: Macmillan.

Watson, D., \& Pennebaker, J. W. (1989). Health complaints, stress, and distress: Exploring the central role of negative affectivity. Psychological Review, 96, 234-254.

Whalen, H. R., \& Lachman, M. E. (2000). Social support and strain from partner, family, and friends: Costs and benefits for men and women in adulthood. Journal of Social and Personal Relationships, 17, 5-30.

Wilkinson, R. (1996). Unhealthy societies: The afflictions of inequality. London: Routledge.

Wright, S. (1934). The method of path coefficients. Annals of Mathematical Statistics, 5, 161-215. 